\title{
INSTRUMENTATION OF AN ICING WIND TUNNEL BASED ON SAE STANDARDS
}

\author{
Reinhard F.A. Puffing ${ }^{1,2)}$, Marian Peciar ${ }^{2)}$, Wolfgang Hassler ${ }^{1)}$ \\ ${ }^{1}$ University of Applied Sciences FH JOANNEUM GrazLuftfahrt/Aviation, Graz, Austria, \\ reinhard.puffing@fh-joanneum.at,wolfgang.hassler@fh-joanneum.at \\ ${ }^{2}$ Institute of Chemical and Hydraulic Machines and Equipment, Faculty of Mechanical \\ Engineering, Slovak University of Technology in Bratislava, Slovak Republic, \\ marian.peciar@stuba.sk
}

Keywords: Icing, tunnel, calibration, equipment

\begin{abstract}
The understanding of aircraft icing phenomena is very important in view of flight safety. In general a distinction is made between rime, glaze and mixed ice, which are each attributed to different icing conditions. The ice shape, which forms on a surface that is exposed to icing conditions depends on a number of physical parameters such as air/droplet temperature and velocity, Liquid Water Content (LWC) and particle diameter. To study icing phenomena experimentally, it is desirable to simulate a wide range of icing conditions. The Society of Automotive Engineering (SAE) has published an Aerospace Recommended Practice (ARP) which includes commonly accepted calibration and acceptance criteria and procedures for icing wind tunnels. This work presents the instrumentation of a small scale icing wind tunnel according to SAE's Recommended Practice (ARP5905).
\end{abstract}

\section{INTRODUCTION}

There are different areas in aviation in which ice accretion and formation can lead to serious operational problems. Thus this issue must be taken into consideration as early as during the design phase of an aircraft with the target of avoiding failures as a result of ice accretion. The most critical parts of an aircraft when exposed to icing conditions are its wings and engines, because a failure of these components can lead to a crash. Airframe icing can increase the drag, decrease the lift and/or reduce the controllability of the aircraft. The icing risk is dependent on the air/droplet temperature, the air/droplet velocity and the cloud type (e.g. cumuli- or stratiform clouds with different LWCs and droplet spectra). For detailed information concerning cloud formation the reader is referred to Rosenfeld and Lensky (1998).

According to the Civil Aviation Authority of New Zealand (2000), there are different kinds of ice which can accrete on surfaces exposed to icing conditions: rime ice, glaze ice (clear ice) and mixed ice.

\section{- $\quad$ Rime ice:}

Rime ice has a rough and milky surface and forms when tiny supercooled water droplets (liquid water droplets with a temperature below the freezing point) hit a surface and freeze immediately.

- $\quad$ Glaze ice (clear ice):

Glaze ice has a smooth surface and forms mostly when rain hits a cold airframe. It can 
also occur when supercooled water droplets hit the surface and freeze partially due to latent heat released during the freezing process, as a result, a certain part of each droplet remains liquid and may freeze later at an aft position. Glaze ice can affect the shape of the airfoil dramatically (typically horn-like ice shapes are formed, Fig. 1) and may lead to serious aerodynamic interference.

- $\quad$ Mixed ice:

Mixed ice is a mixture between rime and glaze ice. Mixed ice is the most common ice form because in most cases the clouds contain droplets with different diameters, which lead to different icing behaviors.

\section{EXTERNAL AIRCRAFT ICING}

External aircraft icing means the process of ice accretion on the outside surfaces which are exposed to icing conditions. It has to be ensured that critical surfaces like wing leading edges, engine cowlings, instrument systems, stabilizers and control surfaces are free of ice during the whole flight. A distinction is made between de-icing and anti-icing. According to the Association of European Airlines (AEA),these processes are defined as (AEA, 2013).

- De-icing is the procedure by which frost, ice, slush or snow is removed from an aircraft in order to provide clean surfaces.

- Anti-icing is a precautionary procedure which provides protection against the formation of frost or ice and the accumulation of snow or slush on treated surfaces of the aircraft for a limited period of time (holdover time).

Fig. 1 shows a typical ice shape, accreted on a wing leading edge, caused by the impingement of supercooled water droplets.

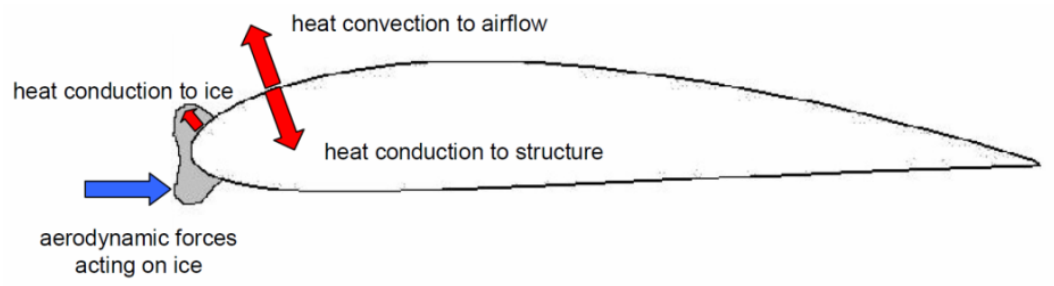

Figure 1: Typical ice shape caused by supercooled water droplets

This paper describes the design of FH JOANNEUM's Icing Wind Tunnel

(FHJIWT).Furthermore, the most important parameters, which are essential for the generation and control of realistic icing conditions, are shown and appropriate measuring techniques to determine these parameters are discussed.

\section{SMALL-SCALE ICING WIND TUNNEL}

FH JOANNEUM's icing wind tunnel (cf. Fig. 2 for a schematic view of the facility) is specially designed for carrying out small-scale icing, de-icing and anti-icing experiments through the impact of super cooled water droplets or, alternatively, ice or snow particles on a test object. The FHJIWT is a closed-loop atmospheric icing wind tunnel of Göttingen type. At the top of the tunnel a continuously controllable fan, powered by an electric motor, is mounted. The air is cooled 
by two heat exchangers in a cross-current flow. By this configuration the air can be cooled down to approximately- $20^{\circ} \mathrm{C}$, depending on the actual ambient temperature.

The cross section of the rectangular test section, which is shown at the bottom of Fig. 2,is $150 \mathrm{~mm}$ by $100 \mathrm{~mm}$ (width by height) and has a length of $300 \mathrm{~mm}$. A volume flow of up to $0.3 \mathrm{~m}^{3} / \mathrm{s}$ can be realized, which is equivalent to a maximum velocity of $20 \mathrm{~m} / \mathrm{s}$ in the empty test section.

To simulate icing conditions, a two-component atomizing nozzle (water and air) is placed in the settling chamber located in front of the bellmouth. The characteristics of the spray (which depends on the water and air pressure) were exactly determined with a Phase Doppler Anemometer (PDA). The corresponding measurements were performed by the Graz University of Technology(Wimmer and Brenn, 2012)and showed that the droplet spectrum can be characterized sufficiently well by a Nukiyama Tanasawa distribution, which is a common distributionin spray characterization. Liquid Water Content (LWC) variations between 3 and $10 \mathrm{~g} / \mathrm{m}^{3}$ and Median Volume Diameters (MVD's) between 35 and 50 microns are possible.

In cases of tests for which super cooled water droplets are needed, pure water in accordance with DIN43530 is used to minimize the probability that the water droplets freeze on their way to the test section. When snow particles are needed, water from the tap is used to feed the atomizing nozzle.

Guide vanes are placed in each corner to minimize secondary flow and to smooth the velocity profile. In front of the test section is a settling chamber, which contains flow straighteners and a turbulence filter followed by a contraction cone which stabilizes and accelerates the flow. The heater, which is located after the fan in the upper section of the tunnel, can be used to run de-icing cycles of the complete icing wind tunnel. This is useful during a long operation period, when ice accretion - for example in the heat exchangers - prejudices the functioning of the device.

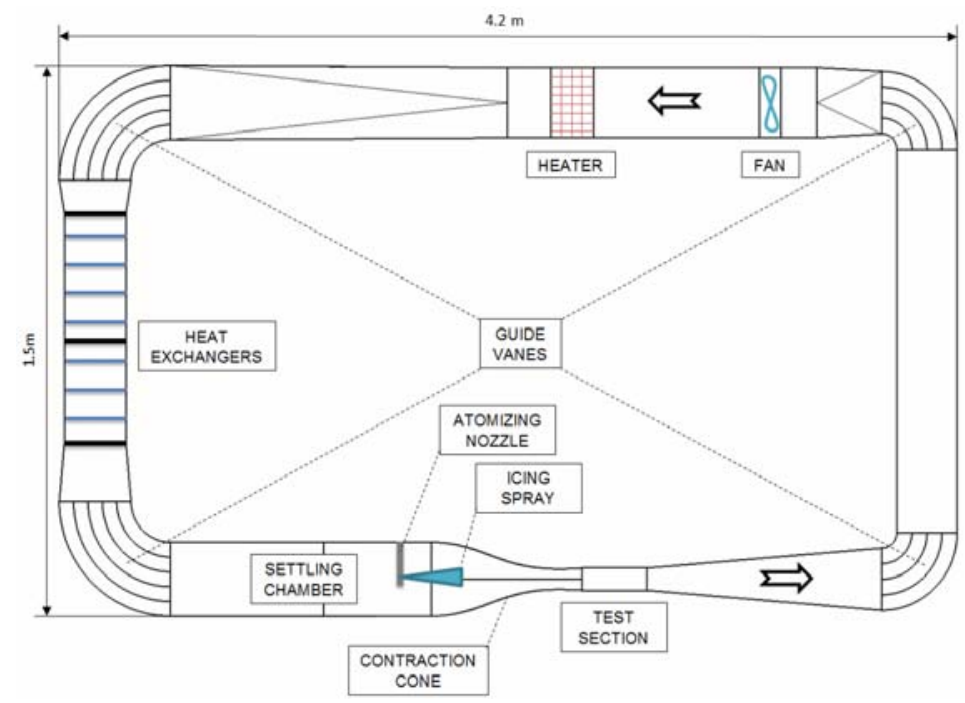

Figure 2: Schematic view of FH JOANNEUM's Icing Wind Tunnel

\section{CALIBRATION PARAMETERS}

In this section the most important parameters, which are essential for the generation and control of realistic icing conditions, are described and appropriate measuring techniques are 
shown.

In general the development of a complete calibration plan, by which the quality and the reproducibility of experiments can be determined and ensured, is recommended. For details regarding the calibration of an icing wind tunnel, the reader is referred to SAE Aerospace(2009) and Arrington et all (2010).

Data acquisition is separated into measurementstaken prior to an experiment andmeasurements made during the experiment. In the latter case it is important that measurement equipment, which is used to determine data continuously (local velocity or temperature, for example), influences the flow as little as possible and works well under icing conditions.

In the former case, calibration tests which are made to determine profile data (velocity or temperature profile, for example) have to be executed usingan empty test section over the complete operating range of the icing wind tunnel, under icing conditions (spray system on)as well as with an inactive spray system. Itis assumed that the water droplets do not influence the flow,which allows an operational condition in which only the air flow of the spray system is on. According to Eckart and Laurien (2009) this assumption is reasonable since the mass fraction of water droplets is small relative to the mass fraction of the dry air - for all operation conditions it is considerably less than 1 percentage point.

\section{MEASUREMENTS PRIOR TO EXPERIMENTS}

The major part of these measurements pertain to the accurate and reproducibledetermination of the flow profiles in the empty test section. This task requires a 2D positioning system by which a particulargrid in the test section (prependicular to the flow direction) can be defined and scanned automatically with different measurement probes. Additionally, the holding time and the number of measured values required can be specified.

- Test section velocity, turbulence intensity and flow angularity: These parameters can simultaneously be measured with a tri-axial constant-temperature anemometer (CTA). In the present case a CTA-probe from Dantec Systems ${ }^{\circledR}$ (55P91) is used. A detailed description of the functional principle of this device can be found in Cameron et all (2007). This measurement provides velocity and turbulence intensity information in three mutually prependicular directions. Thus the flow anglularity can also be calculated from the velocity information.

- Test section temperature:

The temperature profile can be measured with a standard thermocouple which is mounted on the positioning system. Information about thermocouples can be found in, among other sources,Pollock (1971).

- Water droplet diameter:

The determination of the particle spectrum of the two-component atomization nozzle was carried out with the aid of a Phase Doppler Anemometer (PDA) from Dantec Dynamics ${ }^{\circledR}$ by the Graz University of Technology. For a detailed report on the measurements, the reader is referred to Wimmer and Brenn (2012).

- Liquid water content:

The LWC can be determined in several different ways. An overview and comparison of the measurement techniques can be found in Idle (1999).The so-called "rotating cylinder mehtod” representsan acceptable compromise between accuracy, space 
requirements,costs and time requirements. Information on the rotating cylinder method can be found in the work of Howe (1991).

\subsection{Measurements During Experiments}

- $\quad$ Static Pressure:

In icing wind tunnels the icing of certain parts (the heat exchanger, for example) can lead to losses in the quality of the measurement results. The attachment of static pressure ports at critical positions can contribute to the early detection these undesired icing effects. Additionally, the increase in pressure drop resulting from ice accretion on the probe can be documented.

- Volume flow:

Ice accretion in the tunnel results in larger pressure losses, which lead, if the rotational speed (power) of the fan is kept constant, to a lower volume flow. To ensure a constant volume flow(which is equivalent to a constant velocity in the test section) the rotational speed of the fan has to be controlled in accordance with the volume flow. Therefore a differential pressure sensor is integrated at an appropriate position, by which the mean dynamic pressure, hence the velocity, and the volume flow, is determined.

Additionally, the volume flow can be linked with the previously measured velocity and turbulence profiles in the test section, as it is done in NASA's Glenn Icing Research Tunnel (Arrington et all, 2010).

- $\quad$ Local temperature:

Measurement of the local temperature during experiments is necessary to ensure that the quality of the ice accretion measurements is kept at a sufficient level (constant operation). The local temperature measurements can also be linked with the temperature profile in the test section that was measured earlier. Therefore, a set of static thermocouples is positioned in an appropriate position (guide vanes, for example).

In Tab. 1 an overview of all parameters and their appropriate performance targets is shown.

Table 1: Test Section Performance Target (SAE 2009)

\begin{tabular}{|c|c|c|c|c|}
\hline & $\begin{array}{c}\text { Measurement } \\
\text { Instrumentation } \\
\text { Maximum } \\
\text { Uncertainty }\end{array}$ & $\begin{array}{c}\text { Tunnel Centerline } \\
\text { Temporal Stability }\end{array}$ & Spatial Uniformity & Limit Value \\
\hline Airspeed & $\pm 2 \%$ & $2 \%$ & $2 \%$ & $\frac{N}{A}$ \\
\hline $\begin{array}{c}\text { Static Air } \\
\text { Temperature below } \\
-30^{\circ} \mathrm{C}\end{array}$ & $\pm 2 \%$ & $-2 \%$ & $+2 \%$ & $\frac{N}{N}$ \\
\hline
\end{tabular}




\begin{tabular}{|c|c|c|c|c|}
\hline $\begin{array}{c}\text { Static Air } \\
\text { Temperature } \\
\text { between }-30 \text { and } \\
5^{\circ} \mathrm{C} \\
\end{array}$ & $\operatorname{sen} \%$ & $203 \%$ & $\pi 26$ & $\frac{N}{A}$ \\
\hline Flow Angularity & $20.25^{\prime \prime}$ & $\frac{x}{d}$ & $\pm 2^{\prime \prime}$ & $=3^{n}$ \\
\hline \multicolumn{5}{|c|}{ Flow Turbulence } \\
\hline pa (Spray off) & $\pm 02 \pm \%$ & $=\%$ & $<2 x$ & $\%$ \\
\hline pa (Spray on) & $\pm 0.28 \%$ & $=2 \%$ & $<2 \%$ & E\% \\
\hline Pressure Altitude & $\pm=0 \mathrm{~m}$ & $=00 \mathrm{~m}$ & $\frac{N}{A}$ & $\frac{N}{A}$ \\
\hline \multicolumn{5}{|c|}{ Cloud Uniformity Parameters } \\
\hline $\begin{array}{l}\text { Liquid Water } \\
\text { Content }\end{array}$ & $=20 \%$ & $= \pm \%$ & $20 \%$ & $\frac{N}{A}$ \\
\hline $\begin{array}{l}\text { Median Volume } \\
\text { Diameter }\end{array}$ & $\pm 20 \%$ & $=10 \%$ & $\frac{N}{A}$ & $\frac{M}{A}$ \\
\hline Relative Humidity & $\pm \%$ & $\frac{M}{A}$ & $\frac{M}{A}$ & $\frac{\pi}{d}$ \\
\hline
\end{tabular}

\section{CONCLUDING REMARKS}

The design of an icing wind tunnel for aeronautical purposes, the important parameters which define different icing conditions and appropriate measurement techniques have been described. FH JOANNEUM's icing wind tunnel is designed to achieve velocities of up to20 m/s in the empty test section, temperatures down to $-20^{\circ} \mathrm{C}$, LWCs between 3 and $10 \mathrm{~g} / \mathrm{m}^{3}$ and an MVD range from 35 to 50 microns. This makes it possible to cover a wide range of icing conditions.

In general, data acquisition is divided into measurements which are carried out before experiments and continuous measurements made during experiments. In the former case, the velocity, turbulence intensity and temperature profiles, as well as icing parameters such as the LWC and the particle spectrum, are determined at defined operating points. In the latter case, the volume flow and the local temperature are measured and linked with profile data measured earlier. Additionally, static pressure differences are measured to visualize the icing state of internal parts. For every physical parameter described in this paper, an appropriate measuring technique has been pointed out, and references for detailed information have been included. 


\section{REFERENCES}

[1] Arrington, Allan E., et al. Aero Thermal Calibration of the NASA Glenn Icing Research Tunnel (2004 and 2005 Tests). Glenn Research Center, Cleveland, Ohio 44135: National Aeronautics and Space Adminstration, 2010.

[2] Association of European Airlines, (AEA). Recommendations for De-icing / Anti-icing Aeroplanes on the Ground. July 2013.

[3] Cao, Yihua, et al. Numerical simulation of ice accretions on an aircraft wing. Aerospace Science and Technology, Volume 23, 2012.

[4] Civil Aviation Authority of New Zealand. Aircraft Icing Handbook. Handbook. New Zealand: Civil Aviation Authority of New Zealand, 2000.

[5] Howe, John B. Rotating Multicylinder Method for the Measurement of Cloud Liquid-Water Content and Droplet size. Cold Regions Research \& Engineering Laboratory: US Army Corps of Engineers, 1991.

[6] Idle, Robert F. Comparison of Liquid Water Content Measurement Techniques in an Icing Wind Tunnel. Glenn Research Center, Cleveland, Ohio: US Army Research Laboratory, 1999.

[7] Laurien, Eckart and Herbert Oertel jr. Numerische Strömungsmechanik 3. Auflage. Wiesbaden: Vieweg+Teubner, 2009.

[8] Neese, Bill. Aircraft Environmental Systems. Endeavor Books, 1999.

[9] Pollock, D. D. The Theory and Properties of Thermocouple Elements. American Society of Testing and Materials, 1971.

[10] Rosenfeld, Daniel and Itmar M. Lensky. Satellite-Based Insights into Precipitation Formation Processes in Continental and Maritime Convective Clouds. Hebrew University of Jerusalem, Jerusalem, Israel: American Metrological Society, 1998.

[11] SAE Aerospace. Calibration and Acceptance of Icing Wind Tunnels. SAE International, 2009.

[12] Tropea, Cameron, Alexander L. Yarin and John F. Foss. Springer Handbook of Experimental Fluid Mechanics. Vol. 1. Berlin: Springer Verlag, 2997.

[13] Wimmer, Erich and Günter Brenn. Vermessung eines Sprays aus einer Zweistoffdüse im Rahmen des Projektes ICEGRID. Graz: TU Graz, 2012. 